\title{
Q Crossarark Agents of change: The role of healthcare workers in the prevention of nosocomial and occupational tuberculosis
}

Ruvandhi R. Nathavitharana ${ }^{1,2}$, Patricia Bond ${ }^{1}$, Angela Dramowski ${ }^{1,3}$, Koot Kotze ${ }^{1,4}$, Philip Lederer ${ }^{1,5}$, Ingrid Oxley ${ }^{6}$, Jurgens A. Peters ${ }^{1,7}$, Chanel Rossouw ${ }^{1}$, Helene-Mari van der Westhuizen ${ }^{1,4}$, Bart Willems ${ }^{1,8}$, Tiong Xun Ting ${ }^{1,9}$, Arne von Delft ${ }^{1,10}$, Dalene von Delft ${ }^{1}$, Raquel Duarte ${ }^{11,12}$, Edward Nardell ${ }^{13}$, Alimuddin Zumla ${ }^{1,14}$

Available online: 28 February 2017

\section{In this issue}

Editorial

World Tuberculosis Day 2017: strengthening the fight against tuberculosis. I. Solovic (Slovakia) et al.

Breaking the barriers: Migrants and tuberculosis. G. Sotgiu (Italy) et al.

Tuberculosis elimination and the challenge of latent tuberculosis.

A. Matteelli (Italy) et al.

The cursed duet today: Tuberculosis and HIVcoinfection.

S. Tiberi (UK) et al.

The challenge of the new tuberculosis drugs.

S. Tiberi (UK) et al.

Agents of change: The role of healthcare workers in the prevention of nosocomial and occupational tuberculosis.

R. R. Nathavitharana (USA) et al.
1. TB Proof, Cape Town, South Africa

2. Beth Israel Deaconess Medical Center, Division of Infectious Diseases, Boston, MA 02215, USA

3. Paediatric Infectious Diseases, Stellenbosch University, Department of Paediatrics and Child Health, Cape Town, South Africa

4. East London Hospital Complex, East London, South Africa

5. Massachusetts General Hospital, Division of Infectious Diseases, , Boston, MA 02215, USA

6. Nelson Mandela Metropolitan University, Dietetics Division, , Port Elizabeth, South Africa

7. London School of Hygiene and Tropical Medicine, Faculty of Infectious and Tropical Diseases, Clinical Research Department, London, UK

8. Stellenbosch University, Division of Community Health, Faculty of Medicine and Health Sciences, Cape Town, South Africa

9. Clinical Research Center, Sarawak General Hospital, Kuching, Sarawak, Malaysia

10. School of Public Health and Family Medicine, Faculty of Health Sciences, University of Cape Town, 7925 Observatory, South Africa

11. Institute of Public Health, Porto University, EpiUnit, Portugal

12. Centro Hospitalar de Vila Nova de Gaia, Vila Nova de Gaia, Portugal

13. Brigham and Women's Hospital, Division of Global Health and Social Medicine, 02115 Boston, MA, USA

14. University College London, and NIHR Biomedical Research Centre, University College London Hospital, Division of Infection and Immunity, London, UK

Correspondence:

Ruvandhi R. Nathavitharana, Beth Israel Deaconess Medical Center, Harvard Medical School, Division of Infectious Diseases, 110, Francis Street, 02215 Boston, MA, USA.

rnathavi@bidmc.harvard.edu

\section{Summary}

Healthcare workers (HCWs) play a central role in global tuberculosis (TB) elimination efforts but their contributions are undermined by occupational TB. HCWs have higher rates of latent and active TB than the general population due to persistent occupational TB exposure, particularly in settings where there is a high prevalence of undiagnosed TB in healthcare facilities and TB infection control (TB-IC) programmes are absent or poorly implemented. Occupational health programmes in high TB burden settings are often weak or non-existent and thus data that record the extent of the increased risk of occupational TB globally are scarce. HCWs represent a limited resource in high TB burden settings and occupational TB can lead to workforce attrition. Stigma plays a role in delayed 
diagnosis, poor treatment outcomes and impaired well-being in HCWs who develop TB. Ensuring the prioritization and implementation of TB-IC interventions and occupational health programmes, which include robust monitoring and evaluation, is critical to reduce nosocomial TB transmission to patients and HCWs. The provision of preventive therapy for HCWs with latent TB infection (LTBI) can also prevent progression to active TB. Unlike other patient groups, HCWs are in a unique position to serve as agents of change to raise awareness, advocate for necessary resource allocation and implement TB-IC interventions, with appropriate support from dedicated TB-IC officers at the facility and national TB programme level. Students and community health workers (CHWs) must be engaged and involved in these efforts. Nosocomial TB transmission is an urgent public health problem and adopting rights-based approaches can be helpful. However, these efforts cannot succeed without increased political will, supportive legal frameworks and financial investments to support HCWs in efforts to decrease TB transmission.

\section{Introduction}

Tuberculosis (TB) is now the leading cause of adult death globally from an infectious disease, surpassing HIV and malaria [1]. Moreover, TB is airborne, with the main risk activity being breathing. Although healthcare workers (HCWs) have a central role in global TB elimination efforts, their contributions are undermined by the risk of occupational TB. The 2016 WHO Global TB Report estimates that, in 2015, the number of TB cases per 100,000 HCWs was more than double the notification rate in the general adult population [1]. The risk of TB transmission in healthcare and other congregate settings is high [2,3] and nosocomial outbreaks of multidrug-resistant TB (MDR-TB) and extensively drug-resistant TB (XDR-TB) are well documented $[4,5]$. TB infection control (TB-IC) is one of the key components of the second pillar of the WHO End TB strategy [6]. However, limited attention and resources are applied to TB-IC at both the facility and national level, resulting in ongoing nosocomial TB transmission $[2,7]$. This review will discuss some of the major challenges and potential solutions to improve TB-IC efforts with a focus on the role of HCWs, although it is important to emphasize that the risks of nosocomial TB transmission also apply to patients. We start by describing three cases that demonstrate the current reality of occupational TB across HCW groups in high TB burden countries (HBCS).

\section{Case 1 - Russia}

A medical student remembered finding it difficult to breathe the first time she wore a surgical mask in the operating theatre. Outside the theatre, the doctors who taught her did not wear respirators and so she learnt not to do so either. The risks of occupational TB were never discussed, although she was aware that a medical student and a lecturer had previously fallen ill from multidrug-resistant (MDR) TB. She remembered the shock she felt when she received her MDR-TB diagnosis as an intern in her hometown in Malaysia, after completing medical school in Russia. She felt particularly lonely and struggled to come to terms with her diagnosis. In Russia and other Eastern European countries, HCWs have been demonstrated to be up to three times more likely to develop TB (including MDR-TB) than the general population, with the risk demonstrated to be up to 30 90 times higher for clinicians employed in TB-specific facilities [8].

\section{Case 2 - South Africa}

A nurse worked in a privately owned dialysis unit. She had trained and worked in both public and private sector healthcare facilities in South Africa throughout her career but although she had cared for countless patients with TB, she never thought that she herself would be at such high risk. Looking back, she noted that the ventilation in the dialysis unit was poor with no open windows and TB testing or existing diagnoses for patients were never discussed. However, when she developed MDR-TB, she was made to feel like she had done something wrong and was very much affected by the stigma of TB. Although she is extremely grateful to have survived occupational MDR-TB, she developed hearing loss due to aminoglycoside therapy and has been left with post-TB bronchiectasis, which causes frequent exacerbations and impaired lung function. To her knowledge, infection control practices in the dialysis unit have not changed. A recent systematic review demonstrated high rates of latent and active TB in South African HCWs although available data were limited [9].

\section{Case 3 - India}

In November 2015, a senior laboratory technician at a major hospital in Mumbai became the fourth HCW to die from MDR-TB that year. Having diabetes put him at a higher risk of acquiring TB and having a worse outcome from TB but it is unlikely that he had ever received testing or treatment for latent TB. Despite having no direct contact with patients, laboratory staff have an increased risk of developing TB due to exposure to sputum specimens if correct biosafety procedures including wearing personal protective equipment (PPE) are not strictly implemented. Deaths have also been noted in other non-clinical staff including ward attendants and cleaning staff. Despite the adoption of national airborne infection control guidelines in India, site visits have demonstrated that TB-IC is frequently poorly developed and implemented [10]. 


\section{Challenges}

\section{The epidemiology of TB in HCWs}

HCWs globally are at increased risk for TB infection and disease, although rates of occupationally acquired TB are highest in lowand middle-income countries (LMICs) [2,11]. In these settings, drug-resistant TB (DR-TB) also affects HCWs at a greater frequency than the communities they serve $[12,13]$. The increased risk of TB affects all healthcare personnel including community health workers (CHWs), clinical support staff, laboratory workers and health science students $[14,15]$. Clinical staff (nurses and doctors) appear to be at highest risk $[16,17]$. However there is a dearth of data regarding other groups such as ancillary support and administrative staff who may work in clinical areas and CHWs, although at least some studies have demonstrated that these groups are also at considerable risk [9,18-20]. Although HCWs in LMICs may also be at high risk of TB exposure in their communities, studies that have controlled for living conditions confirm additional risk of TB disease attributable to workplace TB exposure [21]. The documented 3 to 6 -fold increased risk of TB is due to persistent occupational TB exposure in the setting of absent or poorly implemented TB-IC programmes $[2,11]$ and a high prevalence of undiagnosed TB in healthcare facilities $[22,23]$. Ironically, accurate data on TB exposure and infection risk in HCWs is most limited from settings with highest TB burden $[9,24]$. Possible factors explaining the paucity of occupational TB data include the lack of national HCW TB surveillance, weak or non-existent occupational health programmes, reluctance among HCWs to disclose a TB diagnosis owing to stigma and the challenge of diagnosing LTBI in TB endemic settings [25]. In some countries, the close association of TB and HIV disease aggravates stigma surrounding a TB diagnosis, resulting in diagnostic and treatment delays among HCWs [25]. The risk of occupationally acquired TB and the adverse consequences for infected HCWs contribute to attrition of HCWs in regions already challenged by severe shortages in human resources for health $[26,27]$.

\section{TB infection control gaps}

Poorly ventilated and overcrowded indoor congregate settings where there are people with infectious but unsuspected TB, such as healthcare facilities, may be responsible for a high proportion of TB transmission in HBCs [3]. To address the risk of nosocomial TB transmission, the World Health Organization (WHO) has proposed the adoption and rigorous implementation of TB-IC measures [28]. These guidelines divide TB-IC measures into different types. Managerial TB-IC measures include leadership and commitment to establish and implement infection control policies at the health facility level [29]. Administrative control measures include the prompt identification and separation of persons with probable TB, emphasizing timely diagnosis and treatment of active TB [30]. Environmental measures include optimized operational structures, including building design and patient flow to decrease the concentration of airborne TB droplet nuclei and to control the directional flow of potentially infectious aerosols [31]. Personal protective TB-IC measures focus on the provision of correctly fitted respirators [31]. However, even if respirators are available, respirator fit testing is often not performed and thus wearing respirators incorrectly offers a false sense of security [32]. Additionally, respiratory protection is typically only worn in instances where patients are being evaluated for known or suspected TB and therefore cannot offer protection from transmission due to unsuspected TB [31]. Despite these clear recommendations for TB-IC, studies have consistently demonstrated the absence of TB-IC programmes in health-care facilities in $\mathrm{HBCs}[2,33]$. The lack of implementation and scale up of these preventative measures, with an emphasis on rapidly diagnosing and treating unsuspected TB, are primarily responsible for nosocomial TB transmission [10,34,35]. In HBCs such as South Africa, poor building design, overcrowding, lack of knowledge and training regarding facility-based IC plans and guidelines, and poor managerial involvement in the design and implementation of local TB-IC policy have been noted as barriers to the implementation of such measures $[36,37]$. It should be mentioned that TB-IC is also often neglected in low and medium incidence countries. A standardized survey tool used to evaluate drug-resistant TB management in several European countries identified the lack of a comprehensive TB-IC plan in all the reference centres surveyed [38]. Administrative and environmental controls in particular were often lacking. Alarmingly despite the availability of PPEs (i.e. respirators for staff and surgical masks for patients), respirator fit testing was also not available at any of these reference centres [32].

\section{Lack of robust occupational health systems}

Accurate surveillance and reporting of TB disease in HCWs in LMICS is crucial to gaining a better understanding of the epidemiology of TB in this high-risk population [39]. Although WHO published recommendations on their global strategy of occupational health for all in 1994 [40] and released their 10-year Global Plan of Action for Workers' Health in 2007 [41], only 31 countries have ratified the Convention on Occupational Health Services [42] and it has been estimated that only 5 to $10 \%$ of workers in developing countries have access to adequate occupational health services [43]. While the impact of the 2014 Ebola epidemic on the health workforce drew attention to the lack of infection control and occupational health services in West Africa [44], despite having a mortality rate comparable to Ebola and causing illness in an estimated 580,000 people annually, DR-TB has not garnered the necessary political will and urgency to prioritize the institution and maintenance of occupational health services in TB endemic countries.

\section{Challenges with treatment and returning to work}

TB treatment, particularly for drug-resistant strains, is daunting. Outcomes for treatment of drug-resistant TB in HCWs are poor, 
with high rates of treatment failure, mortality and therapy related morbidity $[12,13]$. Although HCWs know the rationale for treatment and need for adherence, many have commented that they had little understanding of the true demands of TB and its treatment regimens and the effect that the disease and the antibiotics have on the body until they became patients themselves [45]. Consultations are often pressed for time, leaving little or no time for compassionate conversations that delve into the patient's emotional state or ability to cope with treatment [27]. For HCWs such as CHWs or ancillary staff, as well as foreign HCWs, there may also be language, cultural or educational barriers that affect crucial knowledge transfer. Social support networks may be limited. Side effects such as peripheral neuropathy, ototoxicity and vision loss may be career-ending for HCWs $[27,45,46]$. Although HCWs may have better access to healthcare facilities than other patients, they may encounter greater stigma and be reluctant to engage in care [47]. This also has implications for their ability to return to work. The psychological and financial costs of not being able to return to work may be crippling for HCWs and their families.

Per guidelines from the U.S. Centers for Disease Control, HCWs with TB should be allowed to return to work when they:

- have had three negative AFB sputum smear results collected 8-24 hours apart (at least one of which should be an early morning specimen);

- have responded to anti-TB treatment that should be effective based on drug susceptibility testing results [48].

The assessment of whether a HCW with TB is no longer infectious and can return to work should be made by a physician who has expertise in the management of TB. Notably, HCWs in HBCS are often reluctant to return to healthcare facilities, where they risk re-exposure and reinfection [27].

\section{Stigma and occupational TB}

Despite romanticized perceptions regarding 'consumption' in Victorian times, the language that has subsequently been used within the TB community has undoubtedly contributed to the stigma associated with this preventable and curable disease. Terms such as 'TB suspect' and 'default' have criminal connotations [49] and there has been an increasing emphasis on avoiding the use of such stigmatizing terminology. Goffman's definition of stigma [50] was reworked and applied to HIV by Alonzo and Reynolds [51] who described stigma as being a 'powerful discrediting and tainting social label that radically changes the way individuals view themselves and are viewed as persons.' This definition also introduces the concepts of external and internal stigma.

External stigma is directed towards HCWs by other HCWs. According to Courtwright et al., the commonest cause of stigma is the perceived risk of transmission [52]. HCWs diagnosed with TB are excluded or avoided, often long after the initial high-risk period for transmission. TB is also stigmatized because of its connotations with malnutrition, poverty and HIV, which may prompt open speculation in the workplace about the affected healthcare worker's immune status $[53,54]$.

Internal stigma is directed by HCWs towards themselves. Feelings of isolation and shame associated with TB can lead to withdrawal from the community. One of the symbols of the contagious nature of TB, and hence also the stigma associated with it, is the mask. Interestingly, although masks are worn routinely in some clinical environments like the operating theatre and in certain countries when using public transport, patients wearing masks to reduce TB transmission report feeling stigmatized and HCWs wearing respirators for protection find that this creates a barrier between them and their patients $[47,55]$.

There is a need to refine existing TB stigma scales developed for HCWs and measure the impact of various strategies to reduce stigma [56]. Possible interventions include bringing affected HCWs together to support each other [52] or large-scale community-based campaigns like the Unmask Stigma campaign that has taken place on World TB day $[57,58]$. Addressing stigma could have a positive impact on diagnostic delays, treatment outcomes, psychological well-being and awareness about the prevalence of occupational TB.

\section{Solutions}

\section{TB infection control solutions}

The primary aim of the WHO checklist for periodic evaluation of TB-IC in health-care facilities is to prevent the transmission of TB to both patients and HCWs [59]. From a management perspective, a TB-IC plan that includes a person responsible for TB-IC and an adequate budget for TB-IC activities such as training should be available at all health facilities. In addition, all staff should receive TB-IC training at least every two years as recommended by the WHO [59]. Each facility should have administrative IC measures in place, such as FAST (Find cases Actively using cough screening and rapid molecular diagnostics, Separate temporarily and promptly Treat effectively) [30] and environmental control measures such as improving ventilation, decreasing overcrowding and the use of germicidal ultraviolet disinfection [3,31]. These measures should be considered at the outset during the health facility planning process and IC officers should thus be part of advisory committees to architects designing health facilities to give input on TB-IC measures. Although it is essential that HCWs as well as ancillary staff working in patient-care areas should have access to N95 respirators that fit them correctly, this should not preclude concurrent implementation of administrative TB-IC controls [60]. Staff shortages and inadequate training at facilities where TB is treated should be addressed [37]. Regular training on TB-IC along with monitoring of HCWs' and institutional adherence to these measures should occur, so that areas with poor adherence can be identified and remediated. Implementing a comprehensive TB-IC package may seem 
overwhelming. Prioritizing key interventions will be necessary and setting-specific context is important. For example, maximizing natural ventilation will be feasible in healthcare facilities in warmer climates but in colder climates, interventions such as germicidal ultraviolet air disinfection may yield greater benefits [31]. Establishing reporting systems through which HCWs can document TB-IC implementation issues that would require attention at the facility and subsequently failing that, at the NTP level, could help to bridge the gap between TB-IC policy and practice.

\section{Developing and strengthening occupational health systems}

Occupational health programmes should be prioritized, maintained and rigorously evaluated, with an emphasis on electronic data collection to facilitate operational monitoring and evaluation [61]. We advocate that occupation should be added to facility TB patient registers and recorded by national TB programmes so that the epidemiology of occupational TB can be better understood and enable the prioritization of target interventions [39]. Regular occupational screening for TB should be available at each health facility. This involves overcoming challenges such as shortages of tuberculin for skin testing or the costs of interferon gamma release assay testing, both of which are used for the diagnosis of latent TB. Occupational health programmes in TB endemic settings should also offer HIV testing and linkage to care, which should at minimum include the provision of isoniazid preventive therapy (IPT) for HCWs with HIV. The feasibility of relocating HCWs living with HIV to a lower risk clinical area [28] is contentious since the majority of clinical areas in HBCs pose a TB transmission risk due to the high prevalence of undiagnosed TB.

HCWs (regardless of HIV status) in many low prevalence settings have access to treatment for LTBI, an intervention proven over decades to be effective [62-64]. HCWs in high-burden settings should therefore also have an opportunity to prevent their progression from infection to disease through the provision of LTBI therapy, since the risk of progression is higher in high transmission settings. The lack of LTBI treatment for high-risk groups such as HCWS represents not only an important gap in TB control efforts but also one that is within the power of the current healthcare system itself to remediate. Access to rapid molecular diagnostic tests such as Xpert MTB/RIF for active TB diagnosis [65] must be ensured so that healthcare professionals can be promptly tested if they experience any symptoms of TB and start effective therapy based on drug susceptibility testing [28]. Confidentiality should be ensured as far as possible with regard to the outcome of tests, to overcome this barrier to getting tested [61], although it is important that this should not preclude contact screening. Building robust occupational health systems will be an important component for overall TB elimination efforts [42].

\section{How can HCWs be agents of change?}

HCWs should advocate for the adoption of policies aimed at documenting, preventing and addressing nosocomial TB transmission. HCWs are in a unique situation, compared to other populations who are particularly vulnerable to TB, as they may be able to have greater input into developing and implementing such policies to protect not only themselves but also their patients [39]. Although health advocacy has not always been an explicitly expected role for HCWs to fulfill, and while many HCWs may view their area of expertise and responsibility as clinical, the importance of advocacy was stressed in a commission on global health professional education published in The Lancet in 2010 [66] and as part of the CanMEDS framework for physician competency [67].

One approach designed to engage HCWs to become agents of change has focused on sharing relatable stories of HCWs affected by tuberculosis to destigmatize occupational TB and dispel the notion that HCWs are "TB Proof", highlighting the shared risk in healthcare facilities [45]. HCWs can also advocate for testing and treatment for LTBI, which has been a neglected issue in HBCs but is now the subject of greater attention. The HCWs described in Cases 1 and 2 were both successfully treated for MDR-TB and are now staunch advocates for HCW workplace safety focused on TB prevention and destigmatization and are working with other agents of change to raise awareness and mobilise the wider HCW community.

\section{The importance of educating and engaging healthcare students}

Students training to become health professionals are exposed to the same occupational hazards as their professional counterparts and resultantly have a high risk of occupational TB [68]. Although students in endemic settings may report perceiving themselves to be at higher risk of TB and are more likely to have received TB-IC training than other HCWs [69], they are not more likely to provide correct examples of TB-IC measures or to use PPE as recommended $[70,71]$. Additionally, it is concerning to note that healthcare students have indicated that they perceive their professional mentors to be similarly aware of the risks of occupational tuberculosis, but report that they do not take the necessary precautions $[47,69]$. Many professional behaviours are modeled on those of mentors [72], and efforts need to be made to ensure that safe practices are emphasized in order to form a foundation for future practices. Engaging future HCWs during this early stage of their training by focusing some intervention efforts on large hospitals that serve as teaching sites can help to facilitate HCWs becoming and remaining agents of change (figure 1).

\section{Human rights and the role of the law}

Legal and regulatory frameworks have a role to play in decreasing TB transmission [73]. There have been scant efforts in highlighting the role and importance of human rights in global 


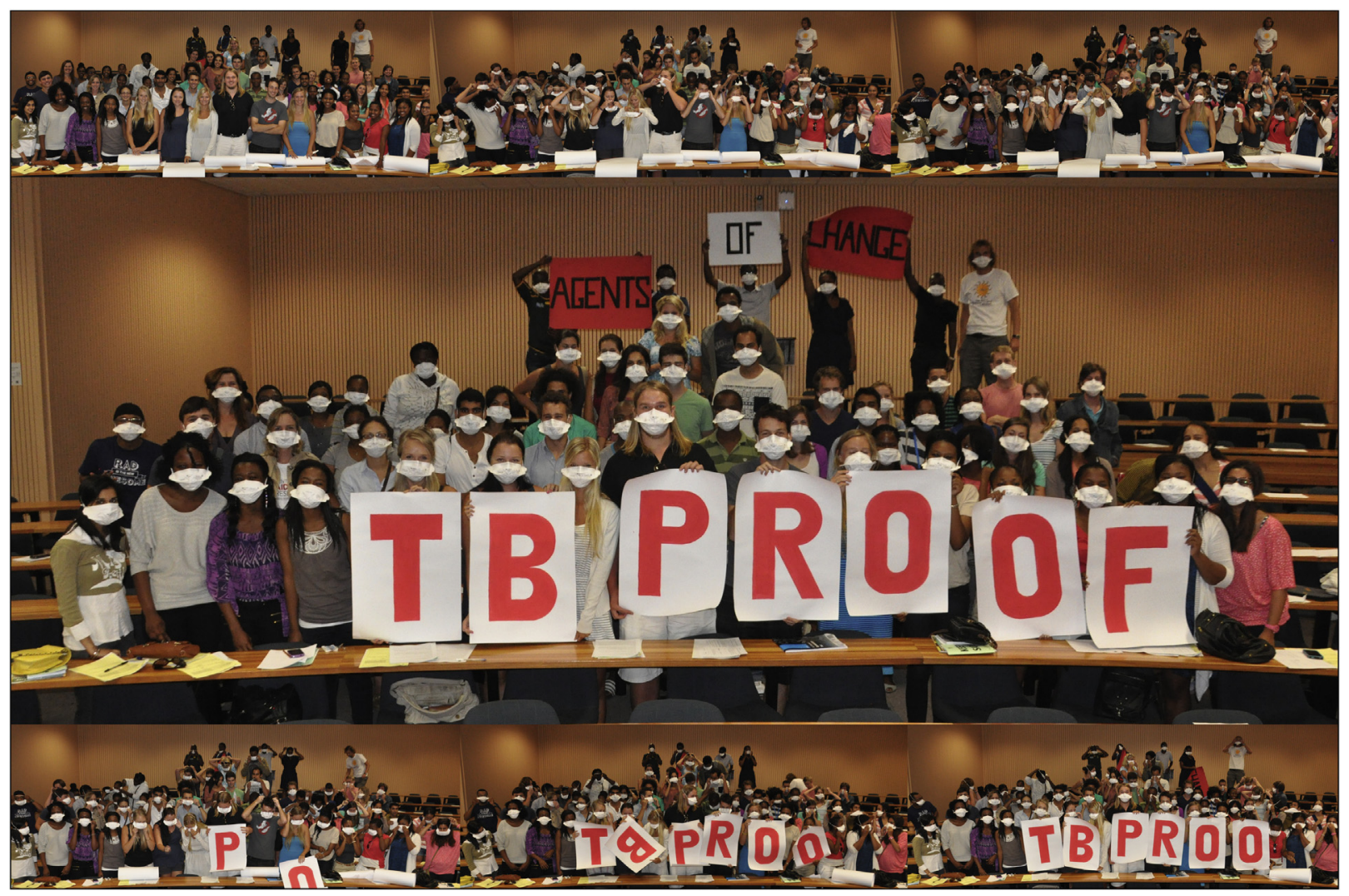

FIGURE 1

TB Proof awareness and advocacy session, Faculty of Medicine and Health Sciences, Stellenbosch University, Cape Town, South Africa Picture credit: TB Proof.

TB control efforts. This reflects the absence or poor implementation of TB-specific legislation, which can articulate the rights of people with $\mathrm{TB}$, the risk of $\mathrm{TB}$ in nosocomial settings and the harms of stigma and discrimination, in TB endemic countries [74].

With regards to TB-IC, the global health community lacks a sound understanding of the law's effect on population health. Although the existence of laws and regulations does not ensure that they will be implemented, they provide a structural framework to guide TB-IC efforts. Consequently, a better understanding of the existing laws that address TB-IC is a prerequisite to assessing their implementation and their effect on practice. A review of laws and regulations described and analysed legislative approaches to TB-IC practices in Botswana, South Africa and Zambia, focusing on selected elements of WHO's TB-IC policy [75]. In all three countries, TB case reporting is required, as is TB surveillance among HCWs. Each country's legal and regulatory framework also addresses the need to respect individuals' rights and privacy while safeguarding public health. Although these laws and regulations should create a strong foundation for TB-IC, poor TB-IC implementation [2] and scant data on occupational TB from LMICs such as these [9] suggests otherwise. Future research should assess the implementation and public health impact of laws and regulations regarding TB-IC.

Laws such as the Occupational Health and Safety Act (OHSA) in South Africa [76] classify TB as an occupational disease, which means that HCWs who develop TB should receive compensation, including occupational sick leave, medical expenses, permanent disability payments and payments to surviving family members. Unfortunately students, CHWs and volunteers with the same exposures typically do not receive the same legal protection despite suffering the same devastating consequences [45]. Legal frameworks must be strengthened to ensure that TB-IC measures are implemented, monitored and evaluated as recommended and to provide care and compensation to all HCWs including trainees and volunteers who are affected by occupational TB. This is an ethical imperative for policy makers [77].

\section{Ongoing scientific challenges}

It is estimated that 1.7 billion people globally are infected with TB [78]. Certain risk factors that increase the likelihood of developing active TB have been identified such as HIV, diabetes 
and tobacco use. However, in other populations that include HCWs, who are more likely to have LTBI than the general population [24], it is not possible to predict who will develop active TB. IPT or alternative LTBI treatment regimens have been recommended in high and low-incidence settings for groups at high risk of TB reactivation, such as people living with HIV and contacts of patients with pulmonary TB [79]. However, there is currently no guidance for HIV-uninfected HCWs (or other HIVuninfected individuals) in $\mathrm{HBCs}$ who are at frequent risk of reexposure and re-infection [80]. This is the subject of debate but based on evidence that treatment of LTBI decreases the risk of future reactivation to TB disease [62-64] resulting in this being a policy recommendation for low-incidence countries [81], preventive therapy should be recommended and available for HCWs as well as others in HBCs with TB infection despite their re-exposure and re-infection risk. Due to the increasing incidence of MDR- and XDR-TB, there are increasing numbers of people (including HCWs) with latent DR-TB, but there аге no guidelines regarding preventive therapy for DR-TB exposure. Although HCWs in HBCs will typically have received the Mycobacterium bovis Bacille Calmette-Guérin (BCG) vaccine as part of the childhood immunization series, the effectiveness of this vaccine is primarily to reduce the risk of TB meningitis in infants. Data suggests that BCG also reduces the risk of infection [82], but BCG immunity subsequently wanes over time, such that vaccination does not prevent adults from developing TB [83]. Due to the complex biology of Mycobacterium tuberculosis, multiple vaccine strategies are being pursued to:

- prevent TB infection after initial exposure;

- prevent the development of TB disease in those who are infected but asymptomatic;

- to prevent recurrent disease in those who have developed and been treated for TB disease [84].

\section{Conclusions}

TB elimination efforts cannot succeed without increased attention and resources being channeled towards TB-IC and occupational health systems strengthening. Table I demonstrates suggested action points at the individual healthcare facility, National TB Programme and supranational WHO level that are critical to decrease nosocomial TB transmission, which includes occupational TB. A focus on monitoring and evaluating TB-IC

\section{TABLE I}

Suggested action points

\begin{tabular}{|c|c|}
\hline Level of health system & Suggested actions \\
\hline \multirow[t]{7}{*}{ Local facility } & Establish a TB-IC plan in accordance with WHO checklist guidelines with regular monitoring and evaluation (M\&E) \\
\hline & Provide training to and support for dedicated TB-IC officers \\
\hline & Develop peer education sessions that may be strengthened by advocacy from occupational TB survivors \\
\hline & $\begin{array}{l}\text { Implement Occupational Health Programmes that include testing HCWs for development of latent TB infection and } \\
\text { active TB disease and providing treatment for both, along with linkage to HIV testing and care. Confidentiality should } \\
\text { be assured wherever possible but not preclude contact evaluation }\end{array}$ \\
\hline & Occupation should be recorded on TB registry forms \\
\hline & $\begin{array}{l}\text { Identify high-risk areas that are poorly ventilated or overcrowded for mitigation by changing patient flow and/or } \\
\text { implementing strategies such as mechanical ventilation and/or germicidal ultraviolet air disinfection }\end{array}$ \\
\hline & Ensure that fit-tested respirators are available for all staff working in clinical areas, including students \\
\hline \multirow[t]{4}{*}{ National ТВ programme } & Ensure robust M\&E programmes for TB-IC and Occupational Health Programmes \\
\hline & $\begin{array}{l}\text { Include community health workers, at-risk non-clinical hospital staff and students in these programmes and ensure that } \\
\text { they receive adequate training }\end{array}$ \\
\hline & Institute and utilize supportive legal frameworks to ensure that TB-IC implementation occurs along with requisite M\&E \\
\hline & Ensure access to diagnostic testing and treatment for latent and active TB \\
\hline \multirow[t]{3}{*}{ WHO } & $\begin{array}{l}\text { Record annual numbers of HCWs that develop TB infection and disease based on facility case records that should } \\
\text { include occupation as an indicator }\end{array}$ \\
\hline & Provide guidance regarding legal frameworks to support TB-IC and occupational health programmes \\
\hline & $\begin{array}{l}\text { Provide guidance regarding preventive therapy for HIV-uninfected HCWs, including those who may have been exposed } \\
\text { to DR-TB }\end{array}$ \\
\hline
\end{tabular}


interventions is needed to ensure that meaningful improvements are being made. HCWs are uniquely placed as agents of change to raise awareness and decrease stigma regarding occupational TB, advocate for policies supported by legislation and critically to act by implementing the solutions discussed in this review. This can lead to healthcare facilities becoming safer for both HCWs and the patients they serve and enabling the delivery of high quality care, even in under-resourced high TB burden countries. Strong leadership coupled with sustained political commitment, supportive legislative frameworks and adequate financial investment will be critical to achieve these goals.

Funding sources: RRN was supported by a grant from the Harvard Center for AIDS Research (NIAID 2P30AI060354-11, http://cfar.globalhealth. harvard.edu) and an Imperial College Institutional Strategic Support Fund Global Health Fellowship. PL was supported by an NIH T32 award (Al007061). EN was supported by an NIH Fogarty Award (D43TW009379).

Disclosure of interest: the authors declare that they have no competing interest.

\section{References}

[1] World Health Organization. Global Tuberculosis Control. WHO report. Geneva, Switzerland; 2016

[2] Joshi R, Reingold AL, Menzies D, Pai M. Tuberculosis among health-care workers in low- and middle-income countries: a systematic review. Plos Med 2006;3:e494.

[3] Yates TA, Tanser F, Abubakar I. Plan Beta for tuberculosis: it's time to think seriously about poorly ventilated congregate settings. Int J Tuberc Lung Dis 2016;20:5-10.

[4] Gandhi NR, Weissman D, Moodley P, et al. Nosocomial transmission of extensively drugresistant tuberculosis in a rural hospital in South Africa. J Infect Dis 2013;207:9-17.

[5] Gelmanova IY, Keshavjee S, Golubchikova VT, et al. Barriers to successful tuberculosis treatment in Tomsk, Russian Federation: nonadherence, default and the acquisition of multidrug resistance. Bull World Health Organ 2007;85:703-11

[6] Uplekar M, Weil D, Lonnroth K, et al. WHO's new end TB strategy. Lancet 2015;385:1799801.

[7] Auld SCB), Mathema T, Mthiyane T, Ismail N, Moodley P, McDaniel D, et al. HIV-Associated XDR TB is transmitted in households and hospitals in South Africa. Boston, MA: CROI; 2016.

[8] Kruuner A, Danilovitsh M, Pehme L, Laisaar T, Hoffner SE, Katila ML. Tuberculosis as an occupational hazard for workers in Estonia. Int J Tuberc Lung Dis 2001;5:170-6.

[9] Grobler L, Mehtar S, Dheda K, et al. The epidemiology of tuberculosis in health care workers in South Africa: a systematic review. BMC Health Serv Res 2016;16:416.

[10] Parmar MM, Sachdeva KS, Rade K, et al. Airborne infection control in India: Baseline assessment of health facilities. Indian J Tuberc 2015;62:211-7

[11] Baussano I, Nunn P, Williams B, Pivetta E, Bugiani M, Scano F. Tuberculosis among health care workers. Emerg Infect Dis 2011;17:488-94.

[12] Jarand J, Shean K, O'Donnell $M$, et al. Extensively drug-resistant tuberculosis (XDR-
TB) among health care workers in South Africa. Trop Med Int Health 2010;15:1179-84.

[13] O'Donnell MR, Jarand J, Loveday $M$, et al. High incidence of hospital admissions with multidrug-resistant and extensively drugresistant tuberculosis among South African health care workers. Ann Int Med 2010;153:516-22

[14] Silva VM, Cunha AJ, Oliveira JR, et al. Medical students at risk of nosocomial transmission of Mycobacterium tuberculosis. Int J Tuberc Lung Dis 2000;4:420-6.

[15] van Rie A, McCarthy K, Scott L, Dow A, Venter WD, Stevens WS. Prevalence, risk factors and risk perception of tuberculosis infection among medical students and healthcare workers in Johannesburg, South Africa. S Afr Med J 2013;103:853-7.

[16] Tudor C, Van der Walt M, Margot B, et al. Tuberculosis among health care workers in KwaZulu-Natal, South Africa: a retrospective cohort analysis. BMC Public Health 2014; 14:891.

[17] Tudor C, Van der Walt ML, Margot B, et al. Occupational risk factors for tuberculosis among healthcare workers in KwaZulu-Natal. South Africa Clin Infect Dis 2016;62(Suppl 3): S255-61.

[18] Sotgiu G, Arbore AS, Cojocariu V, et al. High risk of tuberculosis in health care workers in Romania. Int J Tuberc Lung Dis 2008;12:60611.

[19] Claassens MM, Sismanidis C, Lawrence KA, et al. Tuberculosis among community-based health care researchers. Int J Tuberc Lung Dis 2010;14:1576-81.

[20] Kranzer K, Bekker LG, van Schaik N, et al. Community health care workers in South Africa are at increased risk for tuberculosis. S Afr Med J 2010;100:224-6.

[21] Galgalo T, Dalal S, Cain KP, et al. Tuberculosis risk among staff of a large public hospital in Kenya. Int J Tuberc Lung Dis 2008;12:949-54.

[22] Kantor HS, Poblete R, Pusateri SL. Nosocomial transmission of tuberculosis from unsuspected disease. Am J Med 1988;84:833-8.
[23] Willingham FF, Schmitz TL, Contreras $M$, et al. Hospital control and multidrug-resistant pulmonary tuberculosis in female patients, Lima, Peru. Emerg Infect Dis 2001;7:123-7.

[24] Nasreen S, Shokoohi M, Malvankar-Mehta MS. Prevalence of latent tuberculosis among health care workers in high burden countries: a systematic review and meta-analysis. Plos One 2016;11:e0164034

[25] Siegel J, Yassi A, Rau A, et al. Workplace interventions to reduce HIV and TB stigma among health care workers - where do we go from here? Global Public Health 2015; 10:995-1007.

[26] Figueroa-Munoz J, Palmer K, Poz MR, Blanc L, Bergstrom K, Raviglione M. The health workforce crisis in TB control: a report from high-burden countries. Hum Res Health 2005;3:2.

[27] Padayatchi N, Daftary A, Moodley T, Madansein $R$, Ramjee $A$. Case series of the longterm psychosocial impact of drug-resistant tuberculosis in HIV-negative medical doctors. Int J Tuberc Lung Dis 2010;14:960-6.

[28] World Health Organization. WHO Report 2009: WHO Policy on TB Infection Control in HealthCare Facilities, Congregate Settings and Households. (Accessed at http://www. whqlibdoc.who.int/publications/2009/ 9789241598323_eng.pdf)

[29] Verkuijl SMK. Protecting our front-liners: occupational tuberculosis prevention through infection control strategies. Clin Infect Dis 2016;62(Suppl. 3):S231-7.

[30] Barrera E, Livchits V, Nardell E. F-A-S-T: a refocused, intensified, administrative tuberculosis transmission control strategy. Int J Tuberc Lung Dis 2015;19:381-4.

[31] Nardell E, Dharmadhikari A. Turning off the spigot: reducing drug-resistant tuberculosis transmission in resource-limited settings. Int Juberc Lung Dis 2010;14:1233-43.

[32] Sotgiu G, D'Ambrosio L, Centis R, et al. TB and $M / X D R-T B$ infection control in European TB reference centres: the Achilles' heel? Eur Respir J 2011;38:1221-3. 
[33] Reid MJ, Saito S, Nash D, Scardigli A, Casalini C, Howard AA. Implementation of tuberculosis infection control measures at HIV care and treatment sites in sub-Saharan Africa. Int J Tuberc Lung Dis 2012;16:1605-12.

[34] Claassens MM, van Schalkwyk C, du Toit E, et al. Tuberculosis in healthcare workers and infection control measures at primary healthcare facilities in South Africa. Plos One 2013:8: e76272.

[35] Kuyinu YA, Mohammed AS, Adeyeye 00, Odugbemi BA, Goodman 00, Odusanya 00. Tuberculosis infection control measures in health care facilities offering tb services in Ikeja local government area, Lagos, South West, Nigeria. BMC Infect Dis 2016:16:126.

[36] Malangu N, Mngomezulu M. Evaluation of tuberculosis infection control measures implemented at primary health care facilities in Kwazulu-Natal province of South Africa. BMC Infect Dis 2015;15:117

[37] Sissolak D, Marais F, Mehtar S. TB infection prevention and control experiences of South African nurses-a phenomenological study. BMC Public Health 2011;11:262

[38] Migliori GB, Sotgiu G, D'Ambrosio L, et al. TB and MDR/XDR-TB in European Union and European Economic Area countries: managed or mismanaged? Eur Respir J 2012;39:619-25

[39] Nathavitharana RR, Peters J, Lederer P, et al. Engaging health-care workers to reduce tuberculosis transmission. Lancet Infect Dis 2016:16:883-5

[40] World Health Organization. In: Global strategy on occupational health for all: The way to health at work. Beijing, China; 1994.

[41] World Health Organization. Global Plan of Action on Workers' Health 2008-2017. Geneva, Switzerland: WHO; 2007.

[42] Lucchini RG, London L. Global occupational health: current challenges and the need for urgent action. Ann Global Health 2014;80: 251-6.

[43] LaDou J. International occupational health. Int J Hyg Environ Health 2003;206:303-13.

[44] Nathavitharana RR, Friedland JS. A tale of two global emergencies: tuberculosis control efforts can learn from the Ebola outbreak. Eur Respir J 2015;46:293-6.

[45] von Delft A, Dramowski A, Sifumba Z, et al. Exposed, but Not Protected: More Is Needed to Prevent Drug-Resistant Tuberculosis in Healthcare Workers and Students. Clin Infect Dis 2016:62(Suppl. 3):S275-80.

[46] Modongo C, Sobota RS, Kesenogile B, et al. Successful MDR-TB treatment regimens including amikacin are associated with high rates of hearing loss. BMC Infect Dis 2014; 14:542.

[47] von Delft A, Dramowski A, Khosa C, et al. Why healthcare workers are sick of TB. Int J Infect Dis 2015:32:147-51.

[48] Jensen PA, Lambert LA, lademarco MF Ridzon R. cdc Guidelines for preventing the transmission of Mycobacterium tuberculosis in health-care settings 2005 MMWR Recommendations and reports: Morbidity and mortality weekly report Recommendations and reports, 54. 2005; p. 1-141.

[49] Frick M, von Delft D, Kumar B. End stigmatizing language in tuberculosis research and practice. BMJ 2015;350:h1479.

[50] Goffman E. Stigma. London, England: Penguin Group; 1963

[51] Alonzo AA, Reynolds NR. Stigma, HIV and AIDS: an exploration and elaboration of a stigma trajectory. Social Sci Med 1995;41: 303-15.

[52] Courtwright A, Turner AN. Tuberculosis and stigmatization: pathways and interventions. Public health reports 2010;125(Suppl. 4): 34-42.

[53] Cramm JM, Finkenflugel HJ, Moller V, Nieboer AP. TB treatment initiation and adherence in a South African community influenced more by perceptions than by knowledge of tuberculosis. BMC public health 2010;10:72.

[54] Deribew A, Abebe G, Apers L, et al. Prejudice and misconceptions about tuberculosis and HIV in rural and urban communities in Ethiopia: a challenge for the TB/HIV control program. BMC public health 2010;10:400.

[55] Dodor EA, Neal K, Kelly S. An exploration of the causes of tuberculosis stigma in an urban district in Ghana. Int I Tuberc Lung Dis 2008; 12:1048-54.

[56] Wouters E, Rau A, Engelbrecht M, et al. The Development and Piloting of parallel scales measuring external and internal HIV and tuberculosis stigma among healthcare workers in the free state province. South Africa Clin Infect Dis 2016:62(Suppl. 3):S244-54.

[57] http://www.unmaskstigma.org [Last accessed on February 16th, 2017].

[58] von Delft A, Dramowski A, Kotze K, Lederer $\mathrm{P}$, Mosidi T, Nathavitharana $\mathrm{R}$, et al. In: UnmaskStigma: a global advocacy initiative to address TB stigma. Liverpool, UK; 2016.

[59] World Health Organization. Checklist for Periodic Evaluation of TB Infection Control in Health-Care Facilities; 2015.

[60] Zelnick JR, Gibbs A, Loveday M, Padayatchi N, O'Donnell MR. Health-care workers' perspectives on workplace safety, infection control, and drug-resistant tuberculosis in a highburden HIV setting. J Public Health Policy 2013;34:388-402.

[61] Yassi A, Adu PA, Nophale L, Zungu M. Learning from a cluster randomized controlled trial to improve healthcare workers' access to prevention and care for tuberculosis and HIV in Free State, South Africa: the pivotal role of information systems. Global Health Action 2016;9:30528

[62] International Union Against Tuberculosis Committee on, Prophylaxis. Efficacy of various durations of isoniazid preventive therapy for tuberculosis: five years of follow-up in the, IUAT., trial. Bull World Health Organ 1982;60 (4):555-64.
[63] Akolo CAl, Shepperd S, Volmink J. Treatment of latent tuberculosis infection in HIV infected persons. Cochrane Database Syst Rev 2010;1: CD000171.

[64] Comstock GWFS, Hammes LM. A controlled trial of community-wide isoniazid prophylaxis in Alaska. Am Rev Respir Dis 1967;95(6): 935-43.

[65] Boehme CC, Nabeta P, Hillemann D, et al. Rapid molecular detection of tuberculosis and rifampin resistance. N Engl J Med 2010;363: 1005-15.

[66] Frenk J, Chen L, Bhutta ZA, et al. Health professionals for a new century: transforming education to strengthen health systems in an interdependent world. Lancet 2010;376: 1923-58.

[67] Frank JR, Snell L, Sherbino J, editors. CanMEDS 2015 Physician Competency Framework. Ottawa: Royal College of Physicians. and Surgeons of Canada; 2015.

[68] Mugerwa H, Byarugaba DK, Mpooya S, et al. High Prevalence of tuberculosis infection among medical students in Makerere University, Kampala: results of a cross sectional study. Arch Public Health 2013;71:7.

[69] Van der Westhuizen HM, Kotze K, Narotam $H$, von Delft A, Willems B, Dramowski A. Knowledge, attitudes and practices regarding TB infection among health science students in a TB-endemic setting. Int J Infect Control 2015;11(4). http://dx.doi.org/10.3396/ iiicv111403015.

[70] McCarthy KM, Scott LE, Gous N, et al. High incidence of latent tuberculous infection among South African health workers: an urgent call for action. Int J Tuberc Lung Dis 2015; 19:647-53.

[71] Teixeira EG, Menzies D, Comstock GW, et al. Latent tuberculosis infection among undergraduate medical students in Rio de Janeiro State, Brazil. Int J Tuberc Lung Dis 2005;9 (8):841-7.

[72] Lin CD, Lin BY, Lin CC, Lee CC. Redesigning a clinical mentoring program for improved outcomes in the clinical training of clerks. Med Education Onl 2015;20:28327.

[73] Citro B, Lyon E, Mankad M, Pandey KR, Gianella C. Developing a human rights-based approach to tuberculosis. Health Hum Rights 2016;18:1-8

[74] London L, Cox H, Coomans F, MultidrugResistant TB:. Implementing the right to health through the right to enjoy the benefits of scientific progress. Health Hum Rights 2016;18:25-41.

[75] Verani AR, Emerson CN, Lederer P, et al. The role of the law in reducing tuberculosis transmission in Botswana, South Africa and Zambia. Bull World Health Organ 2016:94:415-23.

[76] Occupational Health and Safety Act, South Africa. http://www.labour.gov.za/DOL/downloads/ legislation/acts/occupational-health-andsafety/amendments/Amended Act - 
Occupational Health and Safety.pdf [Last accessed on February 16th, 2017].

[77] Boulanger RF, Hunt MR, Benatar SR. Where caring is sharing: evolving ethical considerations in tuberculosis prevention among healthcare workers. Clin Infect Dis 2016;62 (Suppl. 3):S268-74

[78] Houben RM, Dodd PJ. The global burden of latent tuberculosis infection: a re-estimation using mathematical modelling. Plos Med 2016;13(10):e1002152.

[79] Getahun H, Matteelli A, Abubakar I, et al. Management of latent Mycobacterium tuberculosis infection: WHO guidelines for low tuberculosis burden countries. Eur Respir J 2015;46:1563-76.

[80] Ai JW, Ruan QL, Liu QH, Zhang WH. Updates on the risk factors for latent tuberculosis reactivation and their managements. Emerg Microbes Infect 2016;5:e10.

[81] Lonnroth K, Migliori GB, Abubakar I, et al. Towards tuberculosis elimination: an action framework for low-incidence countries. Eur Respir J 2015;45:928-52.

[82] Roy A, Eisenhut M, Harris RJ, et al. Effect of $B C G$ vaccination against Mycobacterium tuberculosis infection in children: systematic review and meta-analysis. BMJ 2014;349: g4643.

[83] Kaufmann SH. Novel tuberculosis vaccination strategies based on understanding the immune response. J Int Med 2010;267: 337-53.

[84] da Costa C, Walker B, Bonavia A. Tuberculosis vaccines-state of the art, and novel approaches to vaccine development. Int J Infect Dis 2015;32:5-12. 